\title{
Stepping through the orientation looking glass: A staged approach for postgraduate students
}

\author{
Helen Wozniak \\ Charles Darwin University \\ Mary Jane Mahony, Tim Lever \\ University of Sydney \\ Jenny Pizzica \\ University of Technology, Sydney
}

\begin{abstract}
Postgraduate coursework is now delivered to a largely mature age study population, in what may be an unfamiliar mix of online and distance learning to many students. This paper reports on a novel approach to student orientation in this new environment. Orientation is conceptualised as a process of transition between the domain of everyday life and the domain of academic study over a period of time commencing prior to enrolment and continuing into formal studies. A schema addressing three dimensions (interpersonal, technical and reflective) was constructed and operationalised as a staged orientation plan (GettingOnTrack). Students are able to move through the three stages participating in activities which align with their needs before, during and after enrolment. This builds on critical concerns reported in earlier literature, highlighting the need for an extended time line and authentic learning tasks in a risk free environment.
\end{abstract}

\section{Introduction}

Postgraduate coursework students typically return to study in an environment substantially different from that of their previous study. Now there is a strong online component, an expectation of online collaborative learning, and an explicit or implicit distance education model, irrespective of whether they are enrolled in branded distance education or in flexible programs using blended learning approaches; where blended learning is an 'integration of face to face and online learning experiences not a layering of one on top of the other' (Garrison \& Kanuka, 2004, p. 99). In contrast with undergraduates, postgraduate students enrol in courses of shorter length with little opportunity in a compact curriculum for developing generic skills to learn in this changed environment: they are expected to 'hit the ground running' with little more than a brief, usually intensive, in person orientation session, or no session at all. This may lead to disadvantage as recently highlighted by the president of the Council of Australian Postgraduate Associations:

...our experience of postgraduates is that often if they don't get support early on in their enrolment for difficulties they are having, the problems are more likely to get worse ... (Rout, 2007) 
The work reported here is a response to this challenge, undertaken within a 'design research' framework where the design is not an end in itself but a tool for investigating and clarifying the underlying design issues requirements (Sandoval, 2004). The design work reported here is certainly not intended as a fully developed 'solution' for the student orientation problem and it would indeed be naive to do so, given the limitations of current knowledge in this area. The aim is rather one of laying ground for future design work through a more focused and explicit formulation of the critical educational design problems to be overcome in delivering effective student orientation services. In this paper we review the literature on student orientation to this new environment and outline a new conceptualisation of orientation for postgraduate coursework students, with a particular focus on two elements: time (as timeline, not as quantity available) and activity structure. We then outline the design of a specific orientation package informed by our theorising, GettingOnTrack, and briefly report initial results of its implementation with students.

\section{Orientation in contemporary learning environments}

Accounts of formal online learning supports and scaffolds for learners new to using online technology to support their learning are sparse. Orientation information usually focuses on enhancing computer skills, navigating around course management systems, and providing FAQs (Ko \& Rossen, 2004). Reports are usually descriptive, indicating the types of sessions that could be included in orientation programs involving a combination of face to face support and online information (Scagnoli, 2001). One approach taken by two teacher preparation programs in Hawaii was to provide a twoday weekend face to face workshop with participants being flown in from dispersed locations (McKimmy \& Leong, 2004). Although they documented an increase in self reported comfort levels using the technology, they acknowledge the need to include social and community building activities in such programs. Universities with a primary or substantial focus on distance and open learning take a broader view expressed in commitment to student support but with most reporting on the support of adults coming to undergraduate study (see, for example, Tait \& Mills 2003).

Relevant research literature (Levy, 2006; Motteram \& Forrester, 2005; Price, Richardson \& Jelfs, 2007), substantial local anecdote and our own earlier research (Wozniak, Mahony, Pizzica \& Koulias, 2007) all also indicate orientation is required both as a presemester activity and as support embedded within the semester. Both must provide opportunities for learners to experiment with the technology with guided learning activities in a safe supported environment and to make mistakes, as Salmon advised in her early work (Salmon, 1998). Orientation activities reported in the literature on online learning, however, indicate only narrow responses to the need for an extended orientation time line.

Levy (2006) provides the most rigorous analysis of the support required for learners engaged in what she terms 'networked learning'. She used an action research project to unpack the key elements of learning to learn in a networked environment and identified four processes required for successful student engagement. Students required an orientation to the features of the learning space, ability to communicate either asynchronously or synchronously, opportunities to develop social networks with other participants and self management skills to cope with information overload and time constraints. She also noted considerable variation in learner readiness with the skills to participate in networked learning environments, indicating that 
addressing this was best supported by providing a non-linear, looser structure to orientation activities. She presents a framework for supporting networked learning that 'reflects the assumption that initial induction, while important, will not be sufficient to support the developmental process, for newcomers to networked learning' (p. 238). This is further supported by the work of Moule (2007), who whilst critiquing the limitations of using Salmon's 5 stage model for learning outside the constructivist model, noted the need for ongoing support for students throughout their online learning experience. Students will continue to require access to support materials beyond any initial orientation period. The conclusion must be that 'orientation' should not be a point in time but a continuum of support, a timeframe extended before and after the commencement of studies.

Furthermore, postgraduate study frequently requires students to work collaboratively online, necessitating the development of new approaches to learning and more sophisticated time management. Researchers examining student engagement with online communication tools suggest that students may need instruction in how to engage more actively in online learning communities (Geer, 2003; Meyer, 2004; Price, et al., 2007). Structuring activities with meaningful peer interaction is known to enhance learning and improve completion rates (Anderson, Annand \& Wark, 2005). Apart from the work of Levy noted above, however, there are few reports of orientation to online learning which address these more sophisticated, generic learning skills, and provide opportunities for practising these skills in a environment not focused on the content of formal study.

\section{Orientation as a process of transition between lives}

The design of the online orientation activities described later in this paper began with an attempt to map out the features of the online student orientation space. This approach aligns with the Levy's (2006) recommendation of an 'orientation to learning space' as the first element of orientation to 'networked' or online learning. Just as important is understanding how the learning space influences the learning itself. The orientation learning space is more than a collection of elements such as online communication tools or community building; the orientation space is most importantly what brings them together. In simplest terms, the approach is one that starts by recognising that in order to successfully orient students to our learning space, we need to orient ourselves to theirs.

The 'bare bones' of the orientation learning space can be distilled more or less directly from the collection of issues canvassed in the literature discussed above. The three main dimensions (see Figure 1) to emerge are those of technology, interpersonal relationships and reflection (self knowledge and direction). These are located in the context of the domains of life, study and the time in which they take place. The domain of life was particularly important for the cohort of students that this resource supported and will be detailed further in the next section. Time provides a continuous core around which the others revolve, clarifying the shape of the orientation learning space. The orientation learning space is a time based 'space' rather than normal walled premises. The space is a linear continuum defined by a starting point, finishing point and milestones to be reached in between, but not by having any particular location. Beyond this conclusion, understanding how the various elements combine around the temporal core is an unstructured process requiring some imaginative guesswork. 


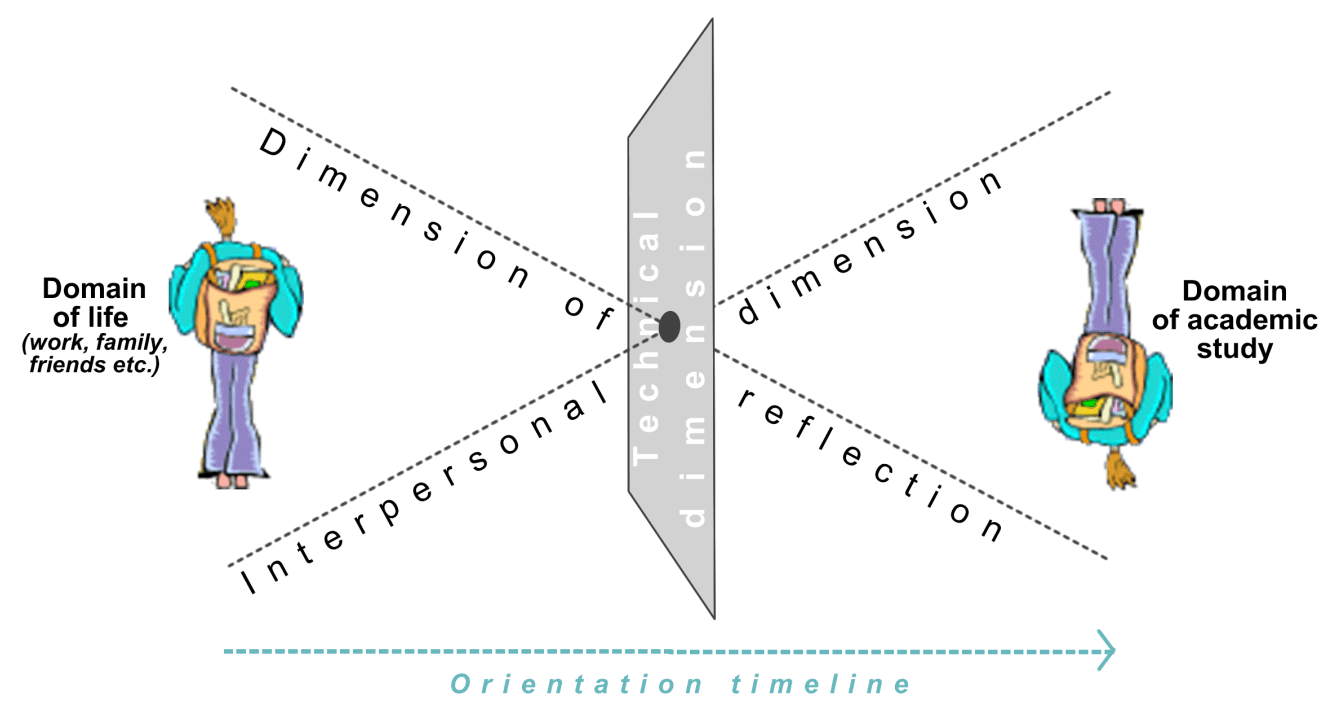

Figure 1: Through the looking glass: the transitional learning space of student orientation

Three essential features of the construct in Figure 1 are:

- the social divide across which the orientation timeline stretches between the domain of students' personal lives and the academic domain;

- key dimensions of learning practice, such as critical reflection and interpersonal interaction, that go from one side to the other but in altered forms as through a refracting layer;

- technology which stands in the middle enabling the orientation process and social and physical distances to be crossed, while at the same introducing its own specific barriers and transition costs.

In brief, the student orientation learning space is conceptualised as a period of reflective and interpersonal realignment traversing the enrolment threshold and mediated by technology. This concept of the orientation space provides a basic framework for starting to think about how the complex combination of physical, social and technical conditions of student orientation might be addressed on a consistent basis along the underlying timeframe. It provides a means of first defining stages for the orientation process, and then asking questions about how various learning dimensions are best addressed at each stage, whether they be technical knowledge, interpersonal relationships or critical reflection. It will not necessarily mean that we will have all the right answers, but provides a way of searching.

This is the framework which underpinned the development of the staged orientation approach, the GettingOnTrack student orientation package, whose features, strengths, and limitations are outlined in the remainder of this paper. 


\section{The design context}

The GettingOnTrack design experiment was carried out at The University of Sydney (the University), a very large (sixteen faculties, of which five address human health), multi-campus Australian university. The University holds a primarily campus based student focus, with the consequence that responsibility for orientation and student support for busy, part time students commencing postgraduate studies as distance (or substantially distance as a result of blended learning strategies) learners has been left to a faculty, school or program. The work described here was a response to concerns expressed anecdotally and in program level feedback by both program coordinators and students, about the lack of systemic orientation in several postgraduate programs In this regard the project aims were both to meet existing expressed needs and to conduct a 'proof of concept' design and development activity. In content and purpose there was some similarity to existing and planned resources reported by the UKOU's Phillips (2003) but without the institutional commitment or resources.

In the initial stages the student audience was limited to postgraduate allied health professionals in one faculty. Later, common interests in addressing the orientation challenge led to an expanded audience including, by the time GettingOnTrack was launched, a wide spectrum of health professionals commencing postgraduate study (e.g. physicians, nurses, occupational therapists, sexual health counsellors, and others) in ten programs delivered in three of the five faculties concerned with human health.

Student characteristics scoped in the design phase not surprisingly demonstrated the diverse needs of student cohorts in health science courses, where the majority of postgraduate students are studying part time whilst employed. Here, maintenance of professional standards whilst working in increasingly demanding and complex work environments commonly requires these mature age professionals to undertake further study to provide adequate patient safety and care. The population's characteristics range along a continuum, from students who are highly experienced in the online environment (or believe they are), to students substantially lacking in experience and/or confidence. Both groups are potentially at risk of stumbling in their substantive studies, the former through their assumptions that they know what is expected; the latter as much through their lack of confidence as through lack of skills and/or experience.

This was in line with the reports by Levy (2006), noting considerable individual differences in learners speed and ease of use of the different components of a networked learning environment, by Moule (2007) who showed that postgraduate health care students lack confidence and are fearful of technology despite being experienced computer users in their work environment, and in a large Australian study of nurses confirming that high workloads, lack of technical assistance and poor access to training and support were barriers to greater use of information technologies within their disciplinary environment (Hegney et al, 2007).

Whilst there has been considerable discourse regarding the assessment of students' readiness for online learning at many levels, from first year students to postgraduate students (Erlich et al., 2005, Shih et al., 2006, \& Pillay et al., 2007), conclusions indicate that satisfaction with online learning and completion of study requires students to have a range of capacities prior to engagement with online learning materials; most notably technical skills, self confidence with computers, self management skills, and comfort with online communication. Pillay recommends that without online coaching 
to provide students with the necessary skills to negotiate online learning environments, students will not complete their study or encourage other students take up the challenge.

\section{Learning design principles and structure}

GettingOnTrack has sequential stages shown in Figure 2. Prior to enrolment (stage 1), prospective students encounter GetReal, an open access website with diagnostic elements driven by user generated input, enabling prospective students to reflectively assess their own readiness for study. Upon enrolment (stage 2), students receive (as a PDF via email) GetStarted, an instruction leaflet encouraging them to login and navigate the institution's learning management system (LMS), WebCT, with simple visual explanations to help them accomplish this. Upon enrolment, but prior to the start of the formal study (stage 3), students gain access to GetLearning, an activity driven website housed within the institution's password protected LMS. GetLearning uses a modularised approach to address development of key attributes required by learners in online environments.

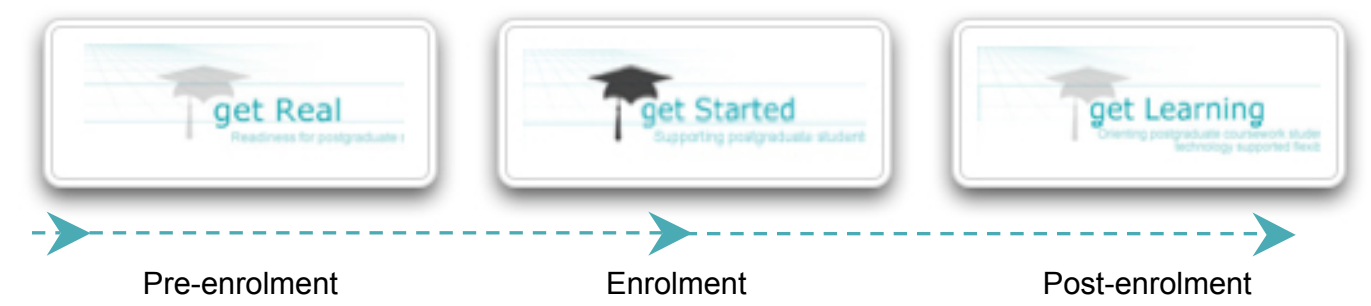

Figure 2: The GettingOnTrack suite

Each of the three stages of GettingOnTrack is described below in relation to the overall conceptual framework, highlighting the learning design dimensions that describe the focus, activity base and underpinning learning supports.

\section{Stage 1: GetReal - pre-enrolment in the timeline}

This first stage of GettingOnTrack focuses on the pre-enrolment phase and the reflective requirements of the enrolment decision. The challenge is to foster prospective students' critical engagement with the implications of their decision to study at a position where those implications and a sense of critical perspective may be a long way off, and where the academic personnel who would normally support the reflection process are unavailable. GetReal compensates for the absence of direct university support by making use of the learner's own community/s as a source of reflective feedback in the 'Study-Life Balance' evaluation tool. It also moves a substantial part of the technology initiation load away from the technical threshold stage to build up confidence and lower the risk of failure which is more likely under the pressures of commencing studies.

The learning design is activity based, where the prospective student engages with a series of reflective choices in place of the more traditional, information led approaches. The design builds on the simple technical concept of the interactive checklist to create an encompassing array of real life study choices. A simple surface question: 'Are you ready for postgraduate online study or not?' draws the prospective student into the reflective maze beneath which there is scaffolded initiation into the real life technical 
challenges of online learning. What might be considered as imperfections of system usability (for example, say, the potential for browser incompatibility) are harnessed as pedagogical triggers developing not only technical skills and confidence but also broader self reliance in dealing with a learning environment in constant change. For example, as Figure 3 illustrates, the three activities assist prospective students to enter a process of reflection about their readiness for online learning, while at the same time trying out aspects of the technology needed for studying online.

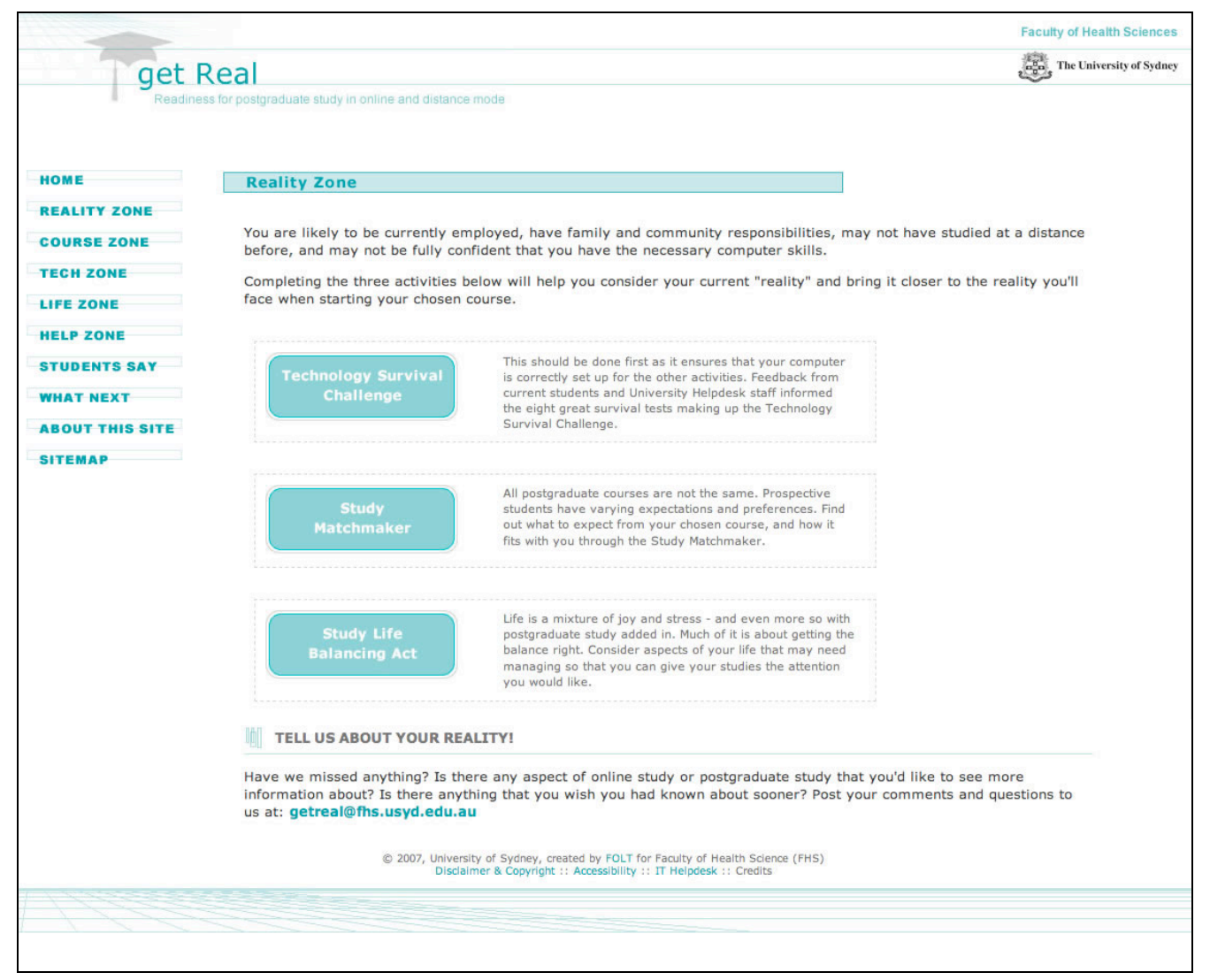

Figure 3: The open access web interface for GetReal

Table 1 shows the relationship between these activities and supporting information for the learner. Finally, a strong social dimension is introduced through a study-life balance activity, designed for sharing between student and others liable to be affected by their study choice. It is a 'family friendly' learning resource.

This open, self access website is designed to address the needs of prospective students with an external inquiry perspective through these features:

- High level of personalised, automated interactivity compensating for human contact not available at this stage.

- Immersive simulation of online learning at a generic level, highlighting key features without actual entry. 
- Graduated level of technical challenge providing a high level of accessibility at the front end and a realistic level of challenge beneath.

- Ease of access for the technically inexperienced.

- Hard to leave without getting a clear, message about the skills and resources required for effective participation in online learning.

- Use of the web medium's instantaneous 'what if' responsiveness to intensify immersive experience, by collapsing the sense of distance that otherwise separates prospective students from the consequences of their study choice. Navigation and layout place choice and the student's decision making role at the centre of the frame (in a literal and visual sense) from first moment of contact.

Table 1: GetReal activities and supports

\begin{tabular}{|l|l|l|}
\hline \multicolumn{1}{|c|}{ Focus } & \multicolumn{1}{|c|}{ Activities } & \multicolumn{1}{c|}{ Supports } \\
\hline Reflective dimension & $\begin{array}{l}\text { Technology survival challenge } \\
\text { Study matchmaker } \\
\text { Study/life balancing act }\end{array}$ & $\begin{array}{l}\text { Tech zone } \\
\text { Course zone } \\
\text { Life zone } \\
\text { Help zone } \\
\text { Where next } \\
\text { Site map }\end{array}$ \\
& & \\
\hline
\end{tabular}

GetReal is located at http:/ / www3.fhs.usyd.edu.au/getreal/. For more detail about its design, see Lever, Mahony \& Wozniak (2007).

\section{Stage 2: GetStarted - at enrolment in the timeline}

GetStarted addresses the needs of students at the technical threshold of the university's LMS. This technical 'how to' bridging document provides all necessary information available at a glance using text and screen shots. It is the most familiar element in the suite as most institutions provide a technical 'how to' manual for their LMS. As a downloadable PDF, it is designed for use in hard copy printed format allowing side by side use alongside the computer in acknowledgement of this preference by many in the target audience.

The GetStarted login guide focuses entirely on the technical threshold stage. The guide provides succinct instructions for new students accessing the university's online learning environment, with referral to help resources in the GetReal site for cases where login fails. The aim is to ensure that all students who are genuinely technically ready for online learning spend as little time as possible dealing with its technicalities, while those students who are not ready are picked up without delay and referred to appropriate help.

Table 2: GetStarted activities and supports

\begin{tabular}{|l|l|l|}
\hline \multicolumn{1}{|c|}{ Focus } & \multicolumn{1}{|c|}{ Activities } & \multicolumn{1}{c|}{ Supports } \\
\hline Technical dimension & $\begin{array}{l}\text { Logging in } \\
\text { Navigating around My eLearning } \\
\text { sites }\end{array}$ & $\begin{array}{l}\text { Logging into USyd eLearning } \\
\text { My eLearning sites } \\
\text { Inside My eLearning sites } \\
\text { Where to get help }\end{array}$ \\
\hline
\end{tabular}

Table 2 shows the relationship between these activities and supporting information for the learner. On the GettingOnTrack timeline, this stage is strongly commended to students at the time when access to the LMS is available to them (consideration of the vexing issue of timely access to enrolment dependent learning resources is outside the 
scope of this paper - see Wozniak, Mahony and Pizzica (in preparation) for discussion of this institutional constraint on student orientation).

\section{Stage 3: GetLearning - post enrolment on the timeline}

GetLearning provides a gradual post-enrolment initiation into the construction of online community, blended with an introduction to the role and responsibilities of the online learner. Utilising the same LMS encountered by students in their university study, GetLearning provides bite sized interactive activities where students can experiment with common online learning tasks in a supportive environment. Its modular design couples each module to the specific skills required of students as they progress in their studies, making these skills and expectations explicit, where they may have been previously unknown or taken for granted. Table 3 outlines the five modules, the skills to be developed in each module and the supports available to assist the learner.

Table 3: GetLearning activities and supports

\begin{tabular}{|c|c|c|}
\hline Focus & Activities & Supports \\
\hline \multirow{10}{*}{$\begin{array}{l}\text { Technical } \\
\text { Interpersonal } \\
\text { Reflective }\end{array}$} & Module 1: & Link to Technology challenge in \\
\hline & Finding your way around & GetReal \\
\hline & - Navigation task and self test & Feedback on self test \\
\hline & - Time management exercise & Link to life zone of GetReal \\
\hline & Module 2: & Discussion activity moderated \\
\hline & $\begin{array}{l}\text { Communicating with others } \\
\text { - Posting and replying to discussion } \\
\text { groups } \\
\text { - Managing university and LMS email }\end{array}$ & $\begin{array}{l}\text { Student use monitored and } \\
\text { individual encouragement } \\
\text { provided by moderators to } \\
\text { lurkers to post }\end{array}$ \\
\hline & Module 3: & Discussion activity moderated \\
\hline & $\begin{array}{l}\text { Building collaborative groups } \\
\text { - Forming online groups } \\
\text { - Participating in online groups for } \\
\text { learning }\end{array}$ & $\begin{array}{l}\text { Tips on how to construct knowledge } \\
\text { in online groups }\end{array}$ \\
\hline & $\begin{array}{l}\text { Module 4: } \\
\text { Getting your assignment done } \\
\text { - Submitting assignments online and } \\
\text { getting feedback } \\
\text { - Searching for online resources }\end{array}$ & $\begin{array}{l}\text { Student use monitored and } \\
\text { individual feedback provided on } \\
\text { assignment submission } \\
\text { Links to university resources for } \\
\text { postgraduate students }\end{array}$ \\
\hline & $\begin{array}{l}\text { Module 5: } \\
\text { Doing the right thing } \\
\text { - Paraphrasing activity } \\
\text { - Endnote activity } \\
\text { - Reflection about group activity in } \\
\quad \text { Module } 3\end{array}$ & $\begin{array}{l}\text { Student comments about academic } \\
\text { honesty } \\
\text { Links to other university resources } \\
\text { such as plagiarism policies, how } \\
\text { to contribute to group work, } \\
\text { academic writing skills }\end{array}$ \\
\hline
\end{tabular}

As students embark on the practice activities, they are provided with timely scaffolds to assist them to hurdle any technical barriers. More confident students can proceed quickly, using only the compact task description before challenging themselves to complete the activity. Students who do not feel as confident or familiar with the environment can use an embedded guide. The guide/s are provided as short, narrated slideshows for a generation of users who customarily use this type of media or who prefer the visual style, and as a downloadable PDF for a generation of users who expect a manual. While sequential completion of the modules is implied, it is not prescribed, allowing for student choice. 


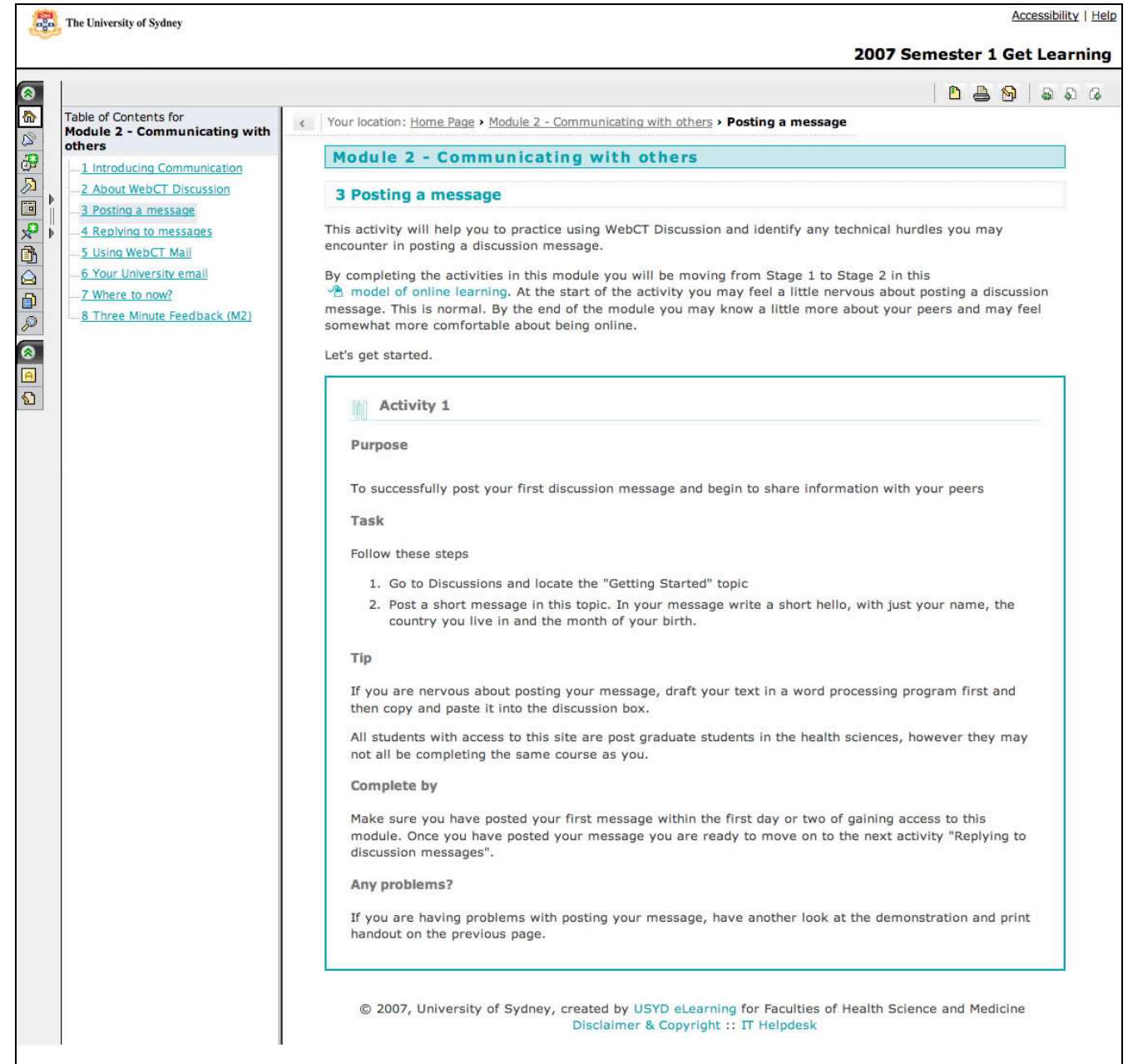

Figure 4: Design of a communication activity in Module 2 of GetLearning

The design of this orientation stage provides a closely scaffolded introduction to the University's online learning environment, while maximising learning opportunities with:

- Activity based orientation site aligned with Salmon's model of online learning (2000).

- Collaborative learning activities in two of the modules to scaffold development of online cognitive presence (Garrison, Anderson, \& Archer, 1999) that encourages inquiry, more reflective dialogue and deeper learning. Figure 4 shows an activity where learners post their first message to an asynchronous discussion forum, an activity which has been identified as posing a significant obstacle to many learners (Levy, 2006). Subsequent activities focus on building supportive groups online and fostering a sense of community online.

- Practice environments not coloured by curriculum expectations facilitating opportunities for experiment and feedback. 
- Exposure to foundation University policies and procedures (e.g. use of email, assignment submission requirements, academic honesty).

\section{Discussion}

GettingOnTrack was conceptualised as an holistic orientation program, not just something to address using technology to support learning, to be undertaken outside formal curricula to address common concerns across a range of online postgraduate coursework programs. In 2007 it was used as 'strongly recommended' by volunteer course coordinators and unit of study coordinators within the broad field of human health. Promotion to students varied according to the interests and action of the individual academic coordinators involved. All students in the nominated academic programs were advised of the suite of resources. Some, but not all, coordinators promoted GetReal to inquiring and early enrolment students. In principle students were given access to the GetLearning site (in the LMS where they accessed all their other unit specific elearning sites) on the first day of Orientation Week if already enrolled, otherwise the day after their enrolment was processed. In practice, access for some cohorts and some individual students was delayed due to institutional enrolment processes based upon on campus student models, collapsing the planned timeline for orientation prior to Week 1 of the semester.

Both formative and summative evaluation was conducted on GettingOnTrack as a whole (during implementation in 2007) and on some of its parts during development and piloting (in 2006). The evaluation design throughout has been driven by stakeholders' views of utility. Reporting these in detail is out of scope of this paper. In brief, detailed analysis of the access patterns of 179 students engaging in the third component, GetLearning across six postgraduate health sciences courses, has provided evidence of the appropriateness of the educational design considerations as well as reinforced the need for students to have access not only at the commencement of their study but also as they progress through the semester (Wozniak, Mahony, Pizzica \& Koulias, 2007). This supports the suggestion by Levy (2006) that learners will continue to discover resources to assist them to learn online, considerably later in the semester and well beyond the initial orientation period.

The design principles were affirmed by student feedback: the extended time line 'extra time at the start would have saved me hours later on' (from a student reviewing the resource who did not have prior access) and authentic learning tasks in a risk free environment: 'It works well because it is like a practice run to the real thing'. We are currently extending analysis to include a different implementation approach (moderated versus unmoderated support) with richer student evaluation data to more fully evaluate the impact of the GettingOnTrack initiative and the design research framework used for this study.

Informal feedback at the end of 2007 was that at least one coordinator was considering connecting GetLearning with her program through a participation assessment in 2008. Such an approach would highlight the value of GetLearning, increasing students' perception of its relevance to them; on the other hand, care would be needed to maintain students' view of it as a 'low risk' environment, that is, the opportunity to explore and make mistakes. 


\section{Summary and conclusions}

A review of published reports on orientation to online learning in a primarily distance learning environment found most reported practices limited in scope and time, with calls for designs with greater learner engagement. A new conceptual model ('Through the looking glass: interpersonal, reflective and technological dimensions') was developed, making more explicit the process of transition and transformation, over time, which commencing students face. Staff and student response in the inaugural implementation year to GettingOnTrack, an operationalisation of the conceptual model to support postgraduate coursework students, suggests the model addresses the realities of commencing postgraduate studies in a wholly or largely online environment.

\section{Acknowledgements}

Gosia Mendrela provided the web development expertise to make GetReal real. The momentum for the elearning strategic project was initiated by Dr Michelle Donelly and Dr Suzanne Snead.

This work was supported in part by the University of Sydney's eLearning Strategic Initiative, under the auspices of the Pro Vice Chancellor (Learning \& Teaching).

\section{References}

Anderson, T., Annand, D. \& Wark, N. (2005). The search for learning community in learner paced distance education: Or, 'Having your cake and eating it, too!' Australasian Journal of Educational Technology, 21(2), 222-241.

http:/ / www.ascilite.org.au/ajet/ajet21/anderson.html

Erlich, Z., Erlich-Philip, I. \& Gal-Ezer, J. (2005). Skills required for participating in CMC courses: An empirical study. Computers $\mathcal{E}$ Education, 44(4), 477-487. [verified 2 May 2009] http: / / www.openu.ac.il/Personal_sites/download/galezer/skills-required.pdf

Garrison, D. R., Anderson, T. \& Archer, W. (1999). Critical inquiry in a text-based environment: Computer conferencing in higher education. The Internet and Higher Education, 2(2-3), 87-105.

Garrison, D. R. \& Kanuka, H. (2004). Blended learning: Uncovering its transformative potential in higher education. The Internet and Higher Education, 7(2), 95-105.

Geer, R. (2003). Initial communication styles and their impact on further interactions in computer conferences. In Interact, integrate, impact: Proceedings ASCILITE Adelaide 2003. http:/ / www.ascilite.org.au/conferences/adelaide03/docs/pdf/194.pdf

Hegney, P. D., Buikstra, E., Eley, R., Fallon, T., Gilmore, V., \& Soar, J. (2007). Nursing and information technology: Final report. [viewed 8 Apr 2009]. http: / / www.anf.org.au/it_project/

Ko, S. \& Rossen, S. (2004). Teaching online: A practical guide. Boston: Houghton Mifflin.

Lever, T., Mahony, M. J. \& Wozniak, H. (2007). GetReal: Building and managing essential academic learning from the academic periphery. In ICT: Providing choices for learners and learning. Proceedings ascilite Singapore 2007.

http:/ / www.ascilite.org.au/conferences/singapore07/ procs/lever.pdf

Levy, P. (2006). 'Living' theory: A pedagogical framework for process support in networked learning. ALT-J: Research in Learning Technology, 14(3), 225-240. [verified 2 May 2009] http:/ / repository.alt.ac.uk/138/ 
McKimmy, P. \& Leong, P. (2004). Online in a hurry: Intensive technology orientation for distance education students in Hawai i teacher preparation programs. Paper presented at the World Conference on Educational Multimedia, Hypermedia and Telecommunications, Chesapeake, VA.

Meyer, K. A. (2004). Evaluating online discussions: Four different frames of analysis. Journal of Asynchronous Learning Networks, 8(2), 101-114. http: / / www.aln.org/publications/jaln/v8n2/pdf/v8n2_meyer.pdf

Motteram, G. \& Forrester, G. (2005). Becoming an online distance learner: what can be learned from students' experiences of induction to distance programmes? Distance Education, 26(3), 281-298.

Moule, P. (2007). Challenging the five-stage model for e-learning: A new approach. ALT-J: Research in Learning Technology, 15(1), 37-50.

Phillips, M. (2003). Delivering learner support on-line: Does the medium affect the message? In A. Tait \& R. Mills (Eds), Rethinking learner support in distance education: Change and continuity in an international context. London, RoutledgeFalmer: 168-184.

Pillay, H., Irving, K. \& Tones, M. (2007). Validation of the diagnostic tool for assessing tertiary students' readiness for online learning. Higher Education Research $\mathcal{E}$ Development, 26(2), $217-$ 234 .

Price, L., Richardson, J. T. E. \& Jelfs, A. (2007). Face-to-face versus online tutoring support in distance education. Studies in Higher Education, 32(1), 1-20.

Rout, M. (2007). VSU adds to postgrad woes. The Australian, 15 August, p. 22. http: / / www.theaustralian.news.com.au/ story /0,25197,22246464-12332,00.html

Salmon, G. (1998, September). Student induction and study preparation online. Paper presented at the Telematics in Education Seminar, Joensuu, Finland. [verified 2 May 2009] http:/ / www.atimod.com/research/presentations / finland2.html

Salmon, G. (2000). E-moderating: The key to teaching and learning online. London: Kogan Page.

Sandoval, W.A. (2004). Developing learning theory by refining learning conjectures embodied in educational designs. Educational Psychologist, 39(4), 213-223.

Scagnoli, N. I. (2001). Student orientations for online programs. Journal of Research on Technology in Education, 34(1), 19-27.

Shih, P., Munoz, D. \& Sanchez, F. (2006). The effect of previous experience with information and communication technologies on performance in a web-based learning program. Computers in Human Behaviour, 22(6), 962-970.

Tait, A. \& Mills, R. (Eds) (2003). Rethinking learner support in distance education: Change and continuity in an international context. London: RoutledgeFalmer.

Wozniak, H., Mahony, M.J., Pizzica, J. \& Koulias M. (2007). How do students 'get learning'? Unexpectedly diverse pathways in an activity-based online orientation site. In ICT: Providing choices for learners and learning. Proceedings ascilite Singapore 2007.

http: / / www.ascilite.org.au/conferences/ singapore07/ procs/ wozniak.pdf

Wozniak, H. \& Silveira, S. (2007). Transforming learning: Using structured online discussions to engage learners. In A. Brew \& J. Sachs (Eds.), The transformed university: The scholarship of teaching and learning in practice. Sydney University Press. http:/ / ses.library.usyd.edu.au/handle/2123/2128 
Helen Wozniak, Associate Professor, Manager Academic Development Team.

Teaching and Learning Quality Group, Charles Darwin University, Darwin, NT 0909, Australia. Email: helen.wozniak@cdu.edu.au

Tim Lever, Instructional Designer, Faculty of Engineering \& Information Technology, The University of Sydney, NSW 2006, Australia. Email: tlever@usyd.edu.au

Dr Mary Jane Mahony, Honorary Senior Lecturer, Faculty of Education \& Social Work, The University of Sydney, NSW 2006, Australia. Email: MJ.Mahony@usyd.edu.au

Jenny Pizzica, Lecturer, Institute for Interactive Media and Learning, University of Technology Sydney, NSW 2007, Australia. Email: jenny.pizzica@uts.edu.au 